\title{
EVALUATION OF TIME-AVERAGE DISPERSION MODELS FOR ESTIMATING PHEROMONE CONCENTRATION IN A DECIDUOUS FOREST ${ }^{1}$
}

\author{
J.S. ELKINTON, ${ }^{2,3}$ R.T. CARDE ${ }^{2,3}$ and C.J. MASON ${ }^{4}$ \\ ${ }^{3}$ Department of Entomology and Pesticide Research Center, Michigan State University, \\ East Lansing, Michigan 48824 \\ ${ }^{4}$ Department of Oceanic and Atmospheric Science, University of Michigan, \\ Ann Arbor, Michigan 48109
}

(Received May 16, 1983; revised October 31, 1983)

\begin{abstract}
The Sutton and more recent Gaussian plume models of atmospheric dispersion were used to estimate downwind concentrations of pheromone in a deciduous forest. Wind measurements from two bivane anemometers were recorded every $12 \mathrm{sec}$ and the pheromone was emitted from a point source $1.6 \mathrm{~m}$ above ground level at known rates. The wingfanning response of individually caged male gypsy moths (Lymantria dispar) at 15 sites situated 20 to $80 \mathrm{~m}$ downwind was used to monitor when pheromone levels were above threshold over a 15 -min interval. Predicted concentrations from these Gaussian-type models at locations where wing fanning occurred were often several orders of magnitude below the known behavioral thresholds determined from wind tunnel tests. Probit analyses of dose-response relationships with these models showed no relationship between predicted dose and actual response. The disparity between the predictions of concentration from these models and the actual response patterns of the male gypsy moth in the field was not unexpected. These time-average models predict concentrations for a fixed position over 3-min or longer intervals, based upon the dispersion coefficients. Thus the models estimate pheromone concentrations for time intervals appreciably longer than required for behavioral response.
\end{abstract}

Key Words-Pheromone dispersion, active space, Sutton model, Gaussian plume model, gypsy moth, Lymantria dispar, Lepidoptera, Lymantriidae.

\footnotetext{
${ }^{1}$ Michigan Agricultural Experiment Station Journal Article No. 10914.

${ }^{2}$ Present address: Department of Entomology, University of Massachusetts, Amherst, Massachusetts 01003 .
} 


\section{INTRODUCTION}

Central to understanding how an organism reacts to airborne pheromone is a delimitation of the pheromone concentrations impinging on the responding individual. In a wind field, concentrations are dependent principally upon the rate of pheromone emission and turbulent dispersion. Wright (1958) and Bossert and Wilson (1963) formulated a conceptual framework, now widely accepted, of pheromone dispersal in the wind, generation of "active spaces," and subsequent response in terms of "threshold." Their pioneering efforts were based upon the Sutton (1953) time-average model for dispersal of gases by atmospheric turbulence and the use of this model to calculate an average concentration of an airborne material emanating from a point source at any location downwind. The Sutton model continues to be widely used in pheromone research, despite theoretical objections raised by Wright (1958) and elaborated upon by Mason (1973), Aylor et al. (1976), Miksad and Kittredge (1979), and Murlis and Jones (1981) of applying time-average models to behavioral reactions that occur over short time intervals. Alternate approaches suggested by Aylor et al. (1976) and Miksad and Kittredge (1979) are, at present, difficult to apply because these models consider dispersion relative to a meandering plume centerline and thus do not estimate the concentration at any point fixed in space. A recent review of dispersion models as they apply to pheromones is given by Elkinton and Cardé (1984).

Pheromone biologists generally have ignored the extensive meteorological literature that has accumulated over the last 25 years on the dispersal of atmospheric pollutants. In this literature the Sutton equations have been supplanted by more recent "time-average" models. Fares et al. (1980) were the first to apply a more general Gaussian plume model to pheromone dispersion. In this study we have mapped the dimensions of a pheromone plume in the field and evaluated the applicability of the Sutton model and the more modern Gaussian plume models using dispersion coefficients utilized by Pasquill (1961), Gifford (1968), and Fares et al. (1980) to describe pheromone dispersion in the wind.

We have used the male gypsy moth, Lymantria dispar L., and the synthetic female pheromone as an exemplar chemical communication system. This choice was justified as follows. (1) The male's diel response periodicity in the field indicates maximal activity in the early afternoon (Cardé et al., 1974), an ideal time for direct behavioral observations. (2) The relatively large size of the male gypsy moth also simplifies monitoring of behavior. (3) The female, as far as is known, uses a single-component attractant. For species with multiple components, Roelofs (1978) proposed that the threshold of pheromone responsiveness differs with the proportion of components in certain pheromone blends. By choosing an organism that evidently releases a single- 
component attractant, we eliminate such potential confounding factors. The synthetic attractant, (+)-disparlure, is available (Cardé et al., 1978). (4) Conceptual models of the male's sequences of response to various concentrations of pheromone are available (Cardé and Hagaman, 1983; Hagaman and Cardé, 1984). (5) No native population of this species near $(<30 \mathrm{~km})$ the test site is known.

\section{METHODS AND MATERIALS}

Selection of a Behavioral Reaction. The size and shape of the active space of a plume of synthetic $(+)$-disparlure in the field were measured by observing the wing-fanning behavior of caged male gypsy moths positioned at various points downwind from the source. In nature, the most important change in behavior that correlates with the male gypsy moth's perception of the "active space" is the change from appetitive (non-pheromone-mediated) flight to upwind anemotaxis. A simple field assay to measure this particular change in behavior has not been devised. However, a change from quiescence to wing fanning while walking is an "earlier" reaction in the sequence of response to pheromone (Hagaman and Cardé, 1984). The proportion and the latency of wing fanning while walking can be related to either concentration or flux of stimulus. The pheromone threshold for this behavior has been determined under the controlled conditions of the wind tunnel milieu (Cardé and Hagaman, 1983). The concentration of (+)-disparlure that elicits a $50 \%$ wingfanning response is ca. $1 \times 10^{-18} \mathrm{~g} / \mathrm{cm}^{3}$.

Experimental Design. The assay for the active space consisted of 15 separate racks positioned simultaneously at various locations downwind of a pheromone source. Each rack had 30 moths held individually in cylindrical wire-mesh cages $(0.45-\mathrm{cm}$ mesh, $7-\mathrm{cm}$ long, $6-\mathrm{cm}$ diameter) with removable tops. The cages were anchored to the $61 \times 61-\mathrm{cm}$ rectangular wire-mesh rack mounted vertically on a steel post. All racks were positioned $1.6 \mathrm{~m}$ above ground (the same height as the source), with the moth cages facing upwind toward the pheromone source and the observer standing behind (downwind). Observations on the occurrence of wing-fanning behavior of each of the 30 moths on all racks were recorded with an audio tape recorder once every $15 \mathrm{sec}$ for the duration of the experiment. Experiments were run for $45 \mathrm{~min}$ and consisted of a 15 -min observation period before releasing pheromone to establish the background rate of spontaneous wing-fanning activity, $15 \mathrm{~min}$ of pheromone release, and a final $15 \mathrm{~min}$ of observation after removal of the pheromone source.

Fifteen racks, each with one observer and 30 moths, were spaced every 10 or $20^{\circ}$ along three arcs (five racks/arc) at 20,40 , and 60 or $80 \mathrm{~m}$ downwind of 
the pheromone source (Figure 1). Racks were put in place at least 30 min prior to the start of the experiment. The experiments were conducted in July and August 1979, beginning at ca. 15:00. A total of 3.4 million observations of individual male wing-fanning behavior at 15 -sec intervals was obtained.

Experimental Site. The experiments were conducted in a mature oakmaple woodlot measuring ca. $200 \times 300 \mathrm{~m}$ on the campus of Michigan State University. The canopy was closed and ca. $20 \mathrm{~m}$ high. The terrain in the woodlot was fairly level ( \pm ca. $2 \mathrm{~m}$ ) and there was very little understory vegetation. The pheromone release site was located at the center of the woodlot at least $10 \mathrm{~m}$ from the nearest tree. Strings radiating from the release site were placed every $20^{\circ}$ at ground level and they extended at least $80 \mathrm{~m}$ in all directions to facilitate positioning of the racks of moths in relation to the pheromone source.

Meteorological Data. Wind speed and direction were monitored by two bivane anemometers (stall speed $=0.3 \mathrm{~m} / \mathrm{sec} ;$ R. M. Young Co., Traverse

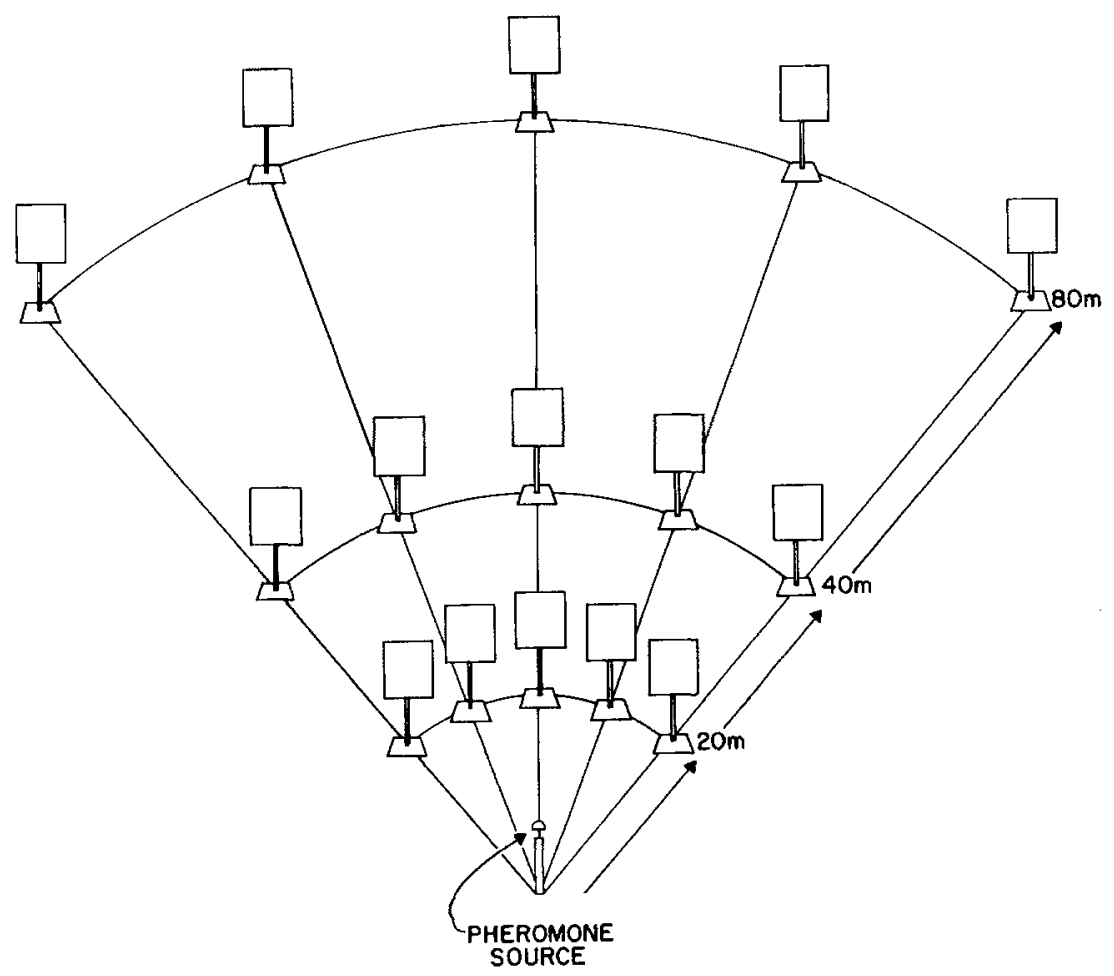

FIG. 1. Spatial layout of racks, each containing 30 male gypsy moths over a $40^{\circ}$ arc at three distances from a pheromone source. 
City, Mich.) positioned $2 \mathrm{~m}$ above ground $10 \mathrm{~m}$ east and $15 \mathrm{~m}$ north of the pheromone source. Air temperature was measured by a Yellow Springs thermistor probe (Yellow Springs, Ohio) in a standard instrument shelter at a site ca. $15 \mathrm{~m}$ northwest of the source. Temperature, wind speed, and both vertical and horizontal wind directions from the two anemometers were recorded and digitized every $12 \mathrm{sec}$ on an Esterline Angus PD 2064 data logger and stored on tape with a Techtran 8000 data cassette for subsequent computer storage and analysis. The acquisition of meteorological data was synchronized within $3 \mathrm{sec}$ of the $15-\mathrm{sec}$ sample interval of the behavioral observations.

Pheromone Source. The pheromone source was $100 \mu \mathrm{g}$ or $10 \mu \mathrm{g}$ of $(+)-$ disparlure (Cardé et al., 1978) dispensed from a cotton wick, 0.8-cm diameter $\times 1.0$-cm long, positioned $1.6 \mathrm{~m}$ above the ground at the center of the woodlot. The pheromone was pipetted onto the wick in $100 \mu 1$ of petroleum ether ca. 16 $\mathrm{hr}$ prior to the experiment and placed overnight in a fume hood to allow the pheromone release rate to stabilize. The cotton-wick dispenser was held on an insect pin affixed to a small cork, which in turn was attached to the top of the 1.6- $\mathrm{m}$ stake. A small piece of aluminum foil between the stake and the cork was replaced daily to prevent contamination of the stake. The pheromone dispenser was placed inside a glass test tube, which in turn was sealed in a glass jar and taken to the field. At the start of the pheromone release period, the jar was opened and the dispenser was removed from the test tube and placed on top of the stake. At the end of the 15-min period of pheromone release, the wick was placed back inside the test tube, sealed in the jar, and removed immediately to a position downwind of the racks of moths.

The release rate from a cotton wick loaded with $100 \mu \mathrm{g}$ of disparlure after $16 \mathrm{hr}$ was ca. 296 and $159 \mathrm{pg} / \mathrm{sec}$, respectively, in wind speeds of 132 and 81 $\mathrm{cm} / \mathrm{sec}$ at $23^{\circ} \mathrm{C}$, as calculated by residue analysis of the dispenser using GLC and $c i s-9,10$-epoxyeicosane as an internal standard. The release rate for each experimental run was calculated by linear interpolation from these two values using the mean wind speed measured by the anemometer.

Rearing of Moths. Male gypsy moths were reared in mass culture (Bell et al., 1981) at the Otis Methods Development Laboratory at Otis Air Base, Massachusetts, and shipped as pupae to Michigan. The pupae were held in paper cups inside of wire-mesh emergence cages in a walk-in screen cage at the northwest corner of the experimental woodlot. Pheromone was not released when the walk-in cage was downwind of the pheromone prior to the experiment. The males remained in the wire-mesh emergence cages for 1-5 days (usually 1-3 days) prior to use in the experiments. On the morning before each afternoon bioassay, the old moths were removed from each rack of 30 cages, the rack was rinsed with acetone to remove possible pheromone residue, and new moths were placed in each cage. 
Calculation of Percentage Wing Fanning and Data Analysis. The moth response data for each grid over $45 \mathrm{~min}$ were transcribed from audio tape (Figure 2). To compare the observed response with the predictions of the various atmospheric dispersion models, we computed the average wind speed and direction for the appropriate time interval beginning at the moment of pheromone release. The estimated concentrations from the Sutton model and the Gaussian plume models were based on a mean wind speed and a direction unique for each sample interval. We also estimated average pheromone flux by multiplying the estimated concentration by the mean wind speed. The estimated average concentration at each location was plotted against the proportion of the 30 moths that initiated wing fanning during the sample period $(3,10,15 \mathrm{~min})$ appropriate for each model. The behavioral sample interval began at each distance at the estimated time of arrival of the plume. This time was determined from the average wind speed starting at the time of pheromone release.

The percentage wing-fanning response at each location for each sample interval $(3,10,15 \mathrm{~min})$ was calculated in two ways. The first method focused on the percentage of males that initiated wing fanning at any time during the

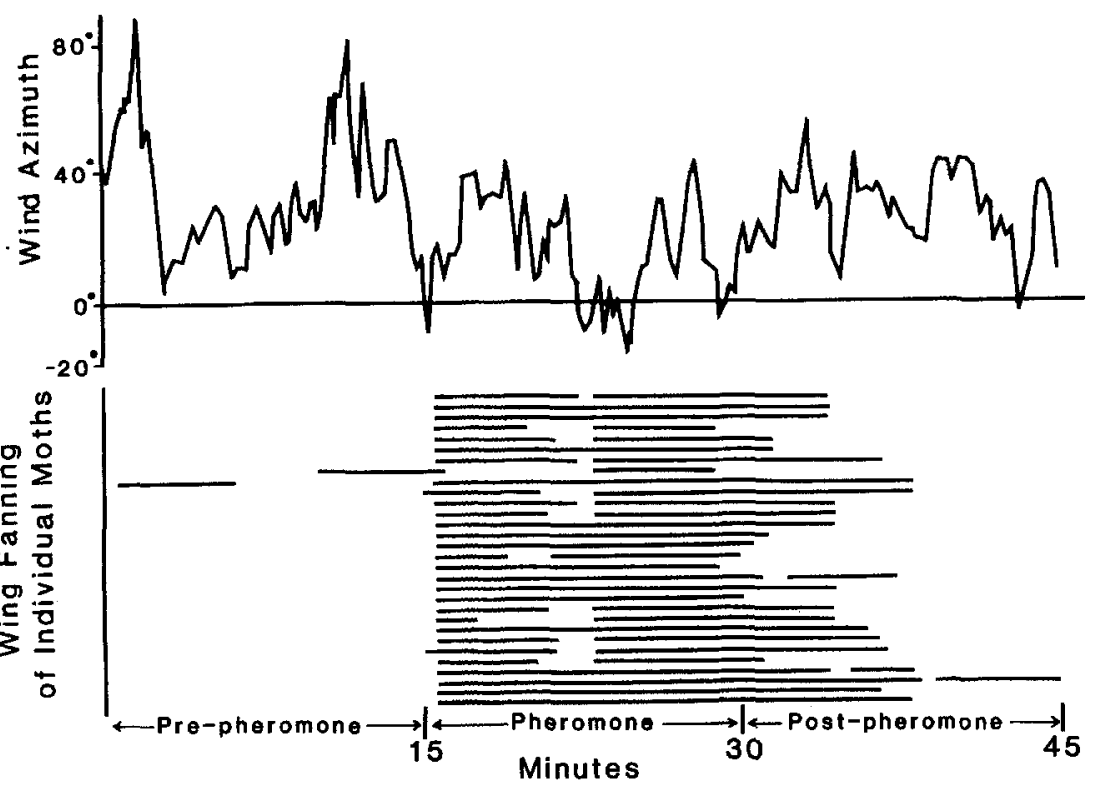

FIG. 2. Wing-fanning behavior of 30 moths at one rack position in the field. The behavior of each moth was recorded every $15 \mathrm{sec}$ during the $45 \mathrm{~min}$ of prepheromone, pheromone, and postpheromone observations. The wind azimuth equals $0^{\circ}$ whenever the wind was blowing directly from the pheromone source toward the moths. 
interval. The estimate of percentage wing fanning was corrected for spontaneous background wing-fanning activity as follows:

$$
\left[\frac{R-B}{N-B}\right] \cdot 100,
$$

where $R$ is the number wing fanning during the interval, $B$ is the number wing fanning during an equal interval prior to pheromone release, and $N$ is the number of moths in the rack minus any that were already fanning immediately prior to the estimated time of plume arrival.

The second way to estimate percentage wing fanning was to compute the total proportion of time spent wing fanning by all 30 moths during the interval. This estimate was corrected for spontaneous wing-fanning activity in the same manner as above [Eq. (1)], except that $N$ is now the total number of seconds in the interval, and $R$ and $B$ are the number of seconds spent wing fanning during and prior to pheromone exposure, respectively.

To compare observed behavior with the model prediction, probit analyses (Finney 1971) were used to generate regression lines of the percentage wing-fanning response transformed to probits against the log concentrations predicted at each location by the Sutton and Gaussian plume models. Regression lines were calculated separately for each distance. For each regression line a $\chi^{2}$ statistic was calculated as well as an $E D_{50}$, which is the concentration of pheromone estimated to produce a $50 \%$ wing-fanning response. A large, statistically significant $\chi^{2}$ occurs when the observed responses depart widely from the values predicted by the regression lines.

Sutton Model. The most widely used pheromone dispersion model is that of Sutton $(1947,1953)$, which was first applied to pheromones by Wright (1958) and Bossert and Wilson (1963). It estimates the concentration $\left(C_{x y z}\right)$ of an airborne material at any point $(x y z)$ downwind of a point source:

$$
C_{x y z}=\frac{2 Q}{\pi C_{y} C_{z} U x^{2-n}} \cdot \exp \left[-x^{n-2}\left[\frac{y^{2}}{C_{y}^{2}}+\frac{z^{2}}{C_{z}^{2}}\right]\right],
$$

where $Q$ is the release rate, $U$ is the mean wind speed, $C_{y}$ and $C_{z}$ are the respective horizontal and vertical diffusion coefficients, and $n$ is a parameter $(0<n<1)$ dependent on the vertical profile of wind velocity. The origin of the coordinate system is the location of the source with the $\mathrm{x}$ axis aligned in the direction of the mean wind, the $y$ axis in the crosswind direction, and the $z$ axis in the vertical. The dispersion coefficients are functions of the atmospheric turbulence, terrain roughness, and vertical windspeed profile. Sutton (1953, p. 292) suggests that with light winds, neutral atmospheric conditions, and level ground, the following approximate value can be used: $C_{y}=0.4 \mathrm{~cm}^{1 / 8}, C_{z}=$ $0.2 \mathrm{~cm}^{1 / 8}$, and $n=0.25$. We have utilized these "typical values" in our test of Sutton's model, as did Wright (1958), Bossert and Wilson (1963), and nearly 
all subsequent applications of Sutton's model to pheromone dispersion. We tested the model performance against a 3-min sampling interval of wingfanning behavior because that is the interval for which the equation was derived. This version of the Sutton model applies to a source located on the surface of a reflecting plane. For a perfectly adsorbing surface the concentration at all points in space is exactly half that given in Eq. (2). For an elevated source, as in this experiment (1.6-m height), Sutton suggests the following equation:

$$
C_{x y z h}=\frac{Q \exp \left(-y^{2} / C_{y}^{2} x^{2-n}\right)}{\pi C_{y} C_{z} U x^{2-n}}\left\{\exp \left[-\frac{(z-h)^{2}}{C_{z}^{2} x^{2-n}}\right]+\exp \left[-\frac{(z+h)^{2}}{C_{z}^{2} x^{2-n}}\right]\right\},
$$

where $h$ is the height of the source above ground. For all sample locations at the same height as the source $(z=h)$, as in this experiment, the estimated concentrations for an elevated source are the same as for a ground-level source if the ground is perfectly adsorbing. If the ground below an elevated source is perfectly or partially reflecting, the concentration in the plane $(x, y, h)$ is elevated by a factor of $<2$, which represents the limiting case. In our test of Sutton's model we have used Eq. (2) since that is the version used by most pheromone biologists regardless of source height. Within the horizontal plane $(x, y, h)$ the difference in concentration for an elevated versus a ground-level source and for a reflecting versus an adsorbing ground surface is miniscule compared to the large range in concentrations (covering many orders of magnitude) estimated for different locations within the plane.

Gaussian Plume Model. In the Gaussian plume model (Pasquill, 1961; Fares, et al. 1980),

$$
\begin{aligned}
C_{x y z h}=\frac{Q}{2 \pi \sigma_{y} \sigma_{z} U} \cdot\left\{\exp \left[-\frac{y^{2}}{2 \sigma_{y}^{2}}\right]\right\} & \\
& \left\{\exp \left[-\frac{(z-h)^{2}}{2 \sigma_{z}^{2}}\right]+\alpha \cdot \exp \left[-\frac{(z+h)^{2}}{2 \sigma_{z}^{2}}\right]\right\},
\end{aligned}
$$

all variables are defined as in the Sutton model, except that the horizontal and vertical dispersion coefficients $\left(\sigma_{y}, \sigma_{z}\right)$ are functions of the downwind distance $(x)$ instead of the constants $C_{y}$ and $C_{z}$ of the Sutton model, and $\alpha$ is a constant $(0<\alpha<1)$ that depends upon the degree of $\lrcorner$ dsorption of material to the ground.

The differences among various applications of the Gaussian plume model are the values or functions chosen for the dispersion coefficients, which are determined experimentally for a specific sample interval and a given set of terrain and atmospheric conditions. Here we use the Pasquill "Prairie Grass" coefficients calculated from the graphs given by Gifford (1968, p. 102), which are appropriate to a 10 - to 60 -min sample interval. We also use the coefficients of Fares et al. (1980) from the TRC-343 data, which were acquired in a forest 
with a 15-min sampling time. The appropriate stability class for each version of the Gaussian plume model (A-F in the Pasquill treatment; buoyant, neutral, or inversion in the model of Fares et al.) was determined from the standard deviation of the wind azimuth measured by the bivane during each run according to Pasquill's formula given by Gifford (1968, p. 102). This method of selecting the appropriate stability class is thus based upon a direct measure of wind turbulence rather than upon the vertical temperature profile. The latter measure pertains to atmospheric turbulence, whereas our method also incorporates the effects of mechanical turbulence, which is substantial beneath a forest canopy. Furthermore, the vertical temperature profile in a woodlot on a typical sunny day is likely to be an inversion below the canopy, with a large lapse rate above and with complex effects on the wind turbulence measured on the ground.

\section{RESULTS}

Validity of the Assay. The moth response to the presence of pheromone was unmistakable at all distances tested (Figure 2, Table 1). Despite some spontaneous wing-fanning activity, the simultaneous initiation of wing fanning (within a 30 -sec period) by most of the 30 moths at a given rack almost never occurred during the prepheromone period but occurred with regularity during the pheromone release period (Table 1). The response to pheromone was highly correlated with the wind direction, at nearly all distances (Table 1). During the pheromone release period, whenever the wind direction shifted directly upwind of the source, as indicated by the meandering track of the bivane, wing fanning usually ensued within a few seconds (Figures $3 a$ and $b$ ).

There was no evidence of any response interaction between the moths in a grid. A sample of 200 wing-fanning events during the prepheromone period revealed that initiation of wing fanning by a particular moth did not significantly increase the probability that adjacent moths would fan $\left(\chi^{2}\right.$ test, $p>0.05$ ).

Following removal of a pheromone source the wing-fanning activity of the moths persisted for several minutes until returning to the background spontaneous rate (Figure 2). The same phenomenon is obvious in Figures 3a and $b$, in which the response continued at a particular rack even though it was no longer directly downwind of the pheromone source. Consequently, wingfanning behavior is a sensitive indicator of the onset but not the cessation of a pheromone stimulus.

Moth Response vs Model Predictions. The occurrence of wing-fanning activity or percentage time spent wing fanning at each of the 15 racks of moths during the 3-, 10-, and 15-min sample intervals corresponds in a rough 


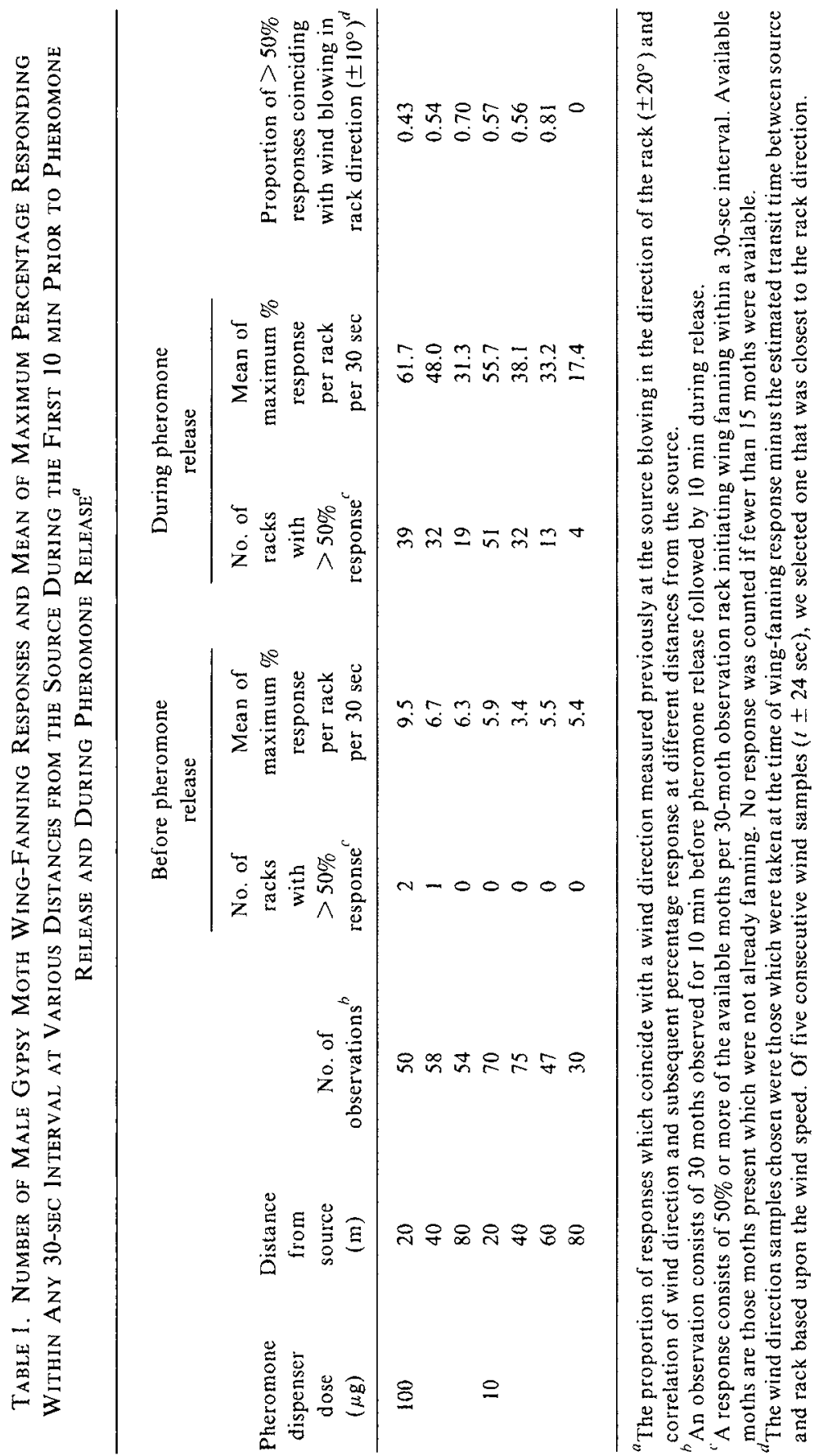



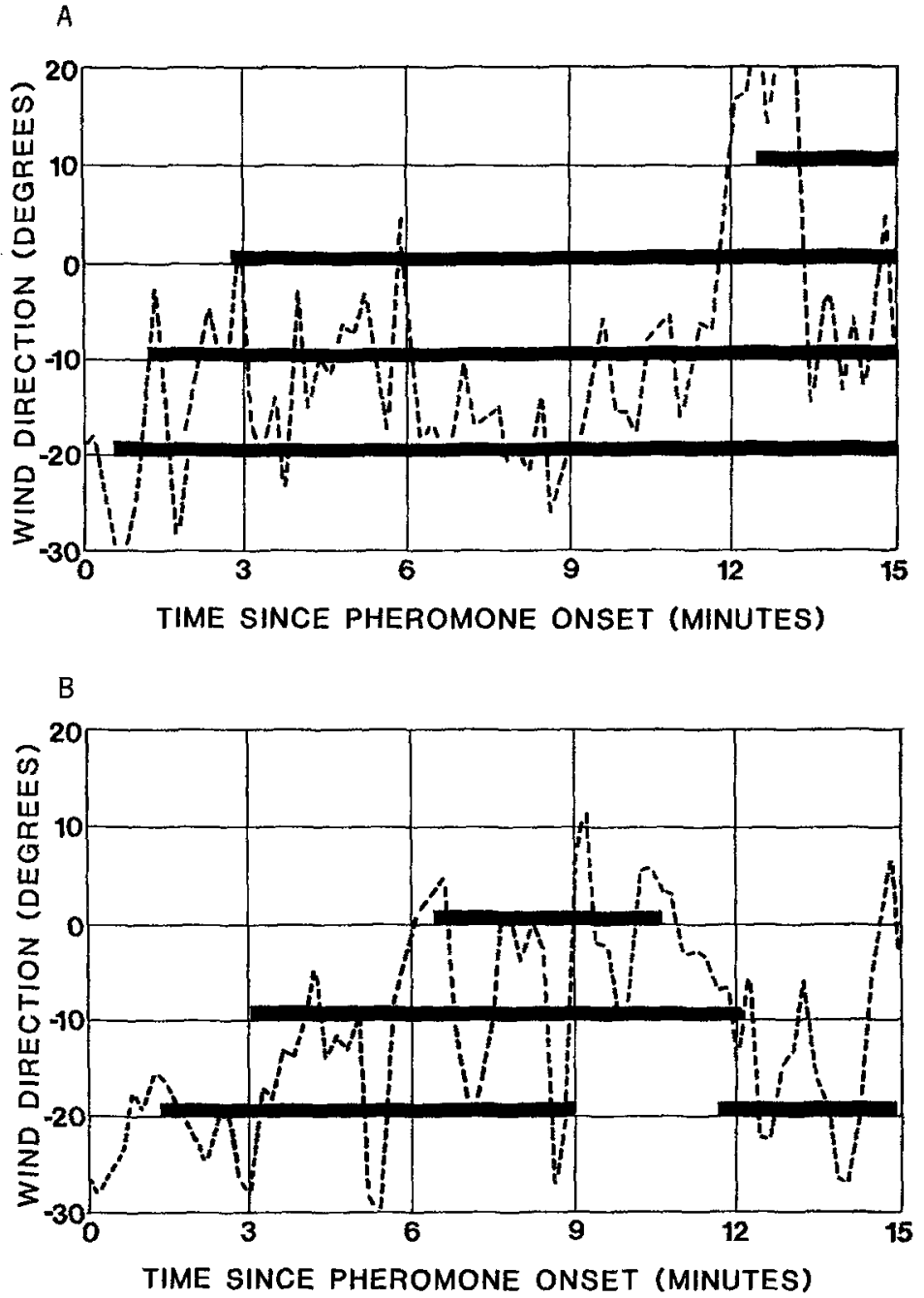

FIG. 3. Coincidence of wind direction (dashed line) measured at the source and the onset of wing-fanning activity (solid bars) among at least $50 \%$ of the males within any $30-$ sec interval after pheromone release at five different locations $(-20,-10,0,+10$, and $+20^{\circ}$ ) at a distance of $20 \mathrm{~m}$ from the source.

qualitative way to the direction and shape of the three Gaussian models considered (Figures 4 and 5). In each case, however, wing fanning occurred at locations well outside of the $1 \times 10^{-18} \mathrm{~g} / \mathrm{cm}^{3}$ isopleths predicted by the three models. This isopleth approximates a concentration which produces a $50 \%$ wing-fanning response in the wind tunnel (Cardé and Hagaman, 1983; Figure 
PERCENT WING FANNING

ISOPLETHS

PERCENT TIME SPENT

WING FANNING

$1 \times 10^{-18} \mathrm{~g} / \mathrm{cm}^{3}$

$1 \times 10^{-20} \mathrm{~g} / \mathrm{cm}^{3}$

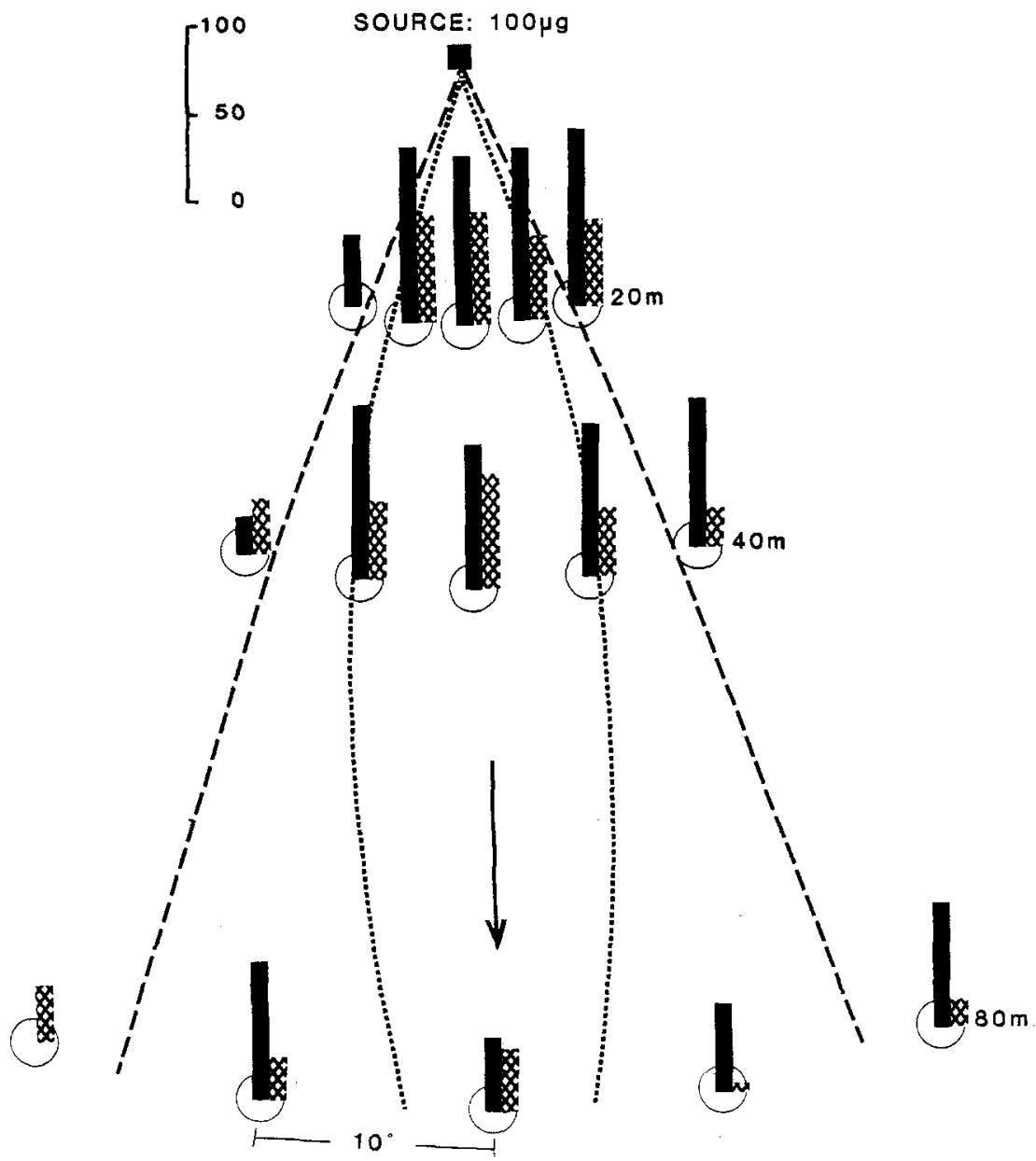

(a)

FIG. 4. $(a-d)$ Concentration isopleths predicted by the Gaussian plume model with Pasquill dispersion coefficients and the percentage wing-fanning response at 15 locations over a 10 -min interval on four different days with a 100 - or $10-\mu \mathrm{g}$ pheromone source. The solid bars represent the percentage of males that wing fanned (corrected for background) during the interval. Hatched bars represent the percentage of time spent wing fanning corrected for background. The $1 \times 10^{-18}$ isopleth is approximately the threshold concentration known to produce a $50 \%$ wing-fanning response in a wind tunnel. 
d percent Wing fanNing

PERCENT TIME SPENT WING FANNING

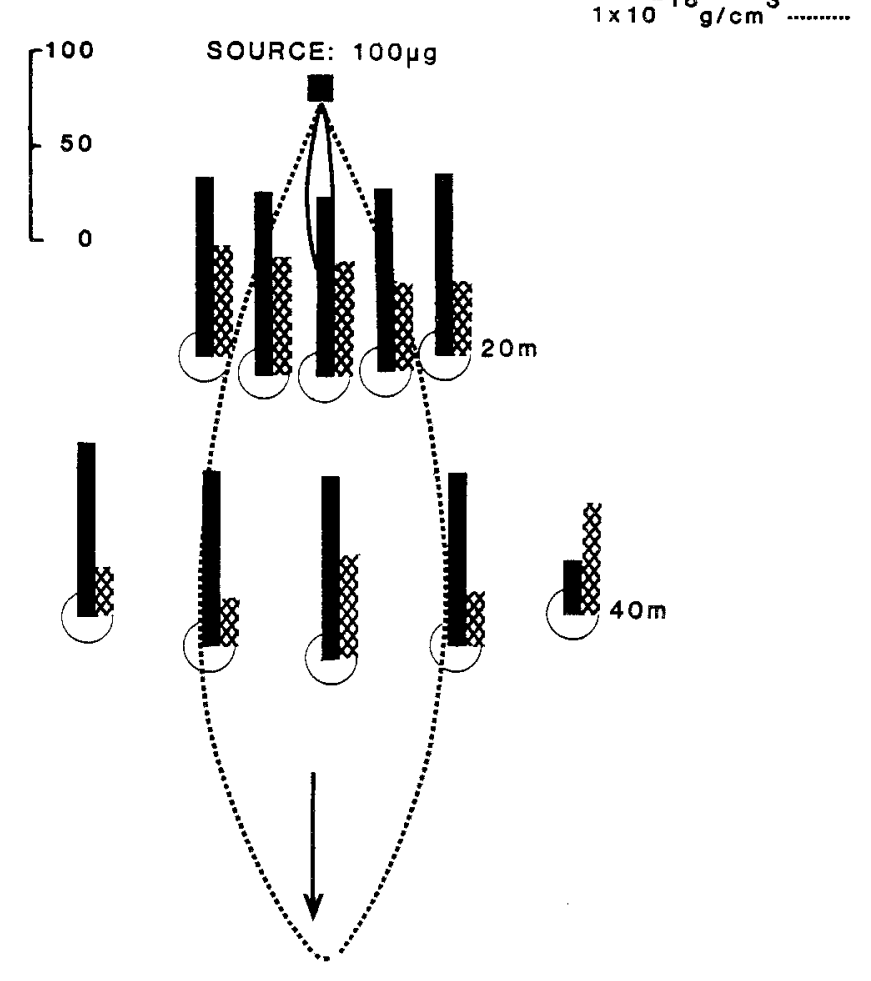

ISOPLETHS

$1 \times 10^{-16} \mathrm{~g} / \mathrm{cm}^{3}$

$1 \times 10^{-18} \mathrm{~g} / \mathrm{cm}^{3}$

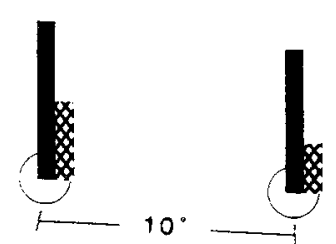

(b)
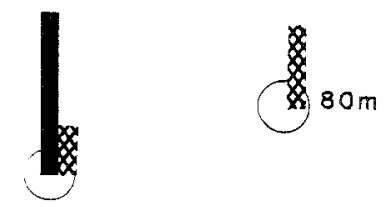

FIG. 4. (Continued) 
- PERCENT WING FANNING PERCENT TIME SPENT WING FANNING
ISOPLETHS

$$
\begin{aligned}
& 1 \times 10^{-18}{\mathrm{~g} / \mathrm{cm}^{3}}^{3} \ldots . . . . . \\
& 1 \times 10^{-20} \mathrm{~g} / \mathrm{cm}^{3} \ldots
\end{aligned}
$$

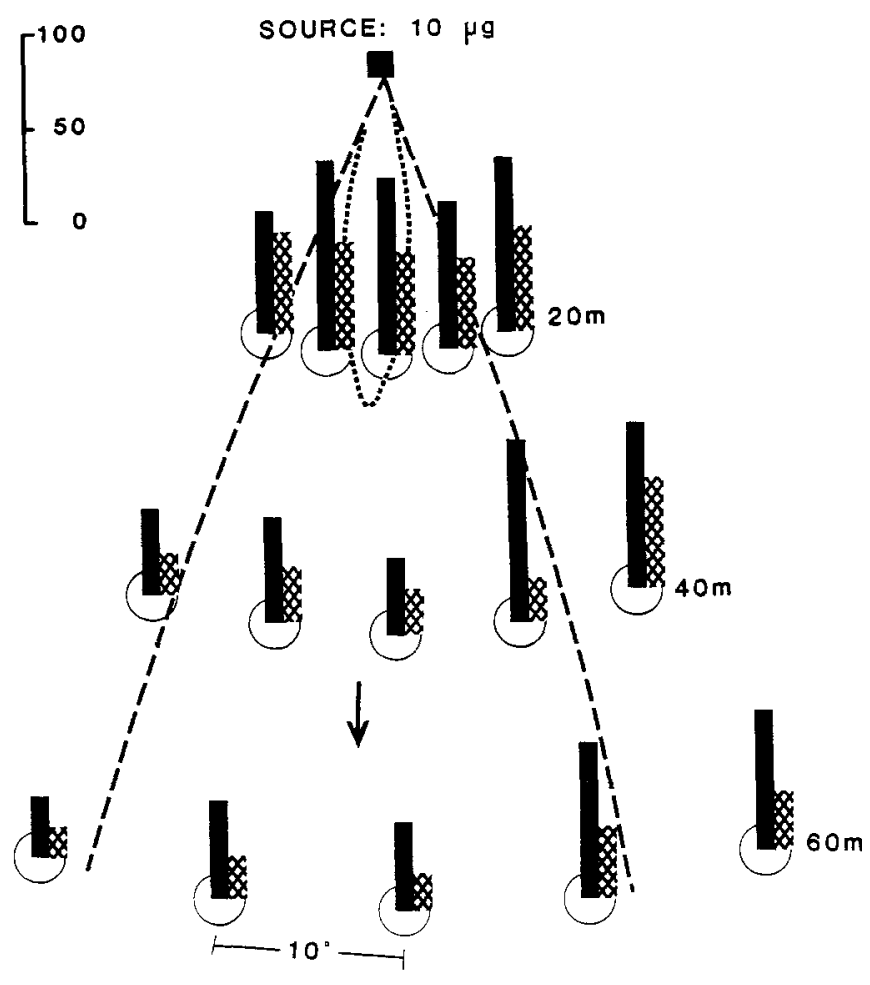

(c)

FIG. 4. (Continued) 

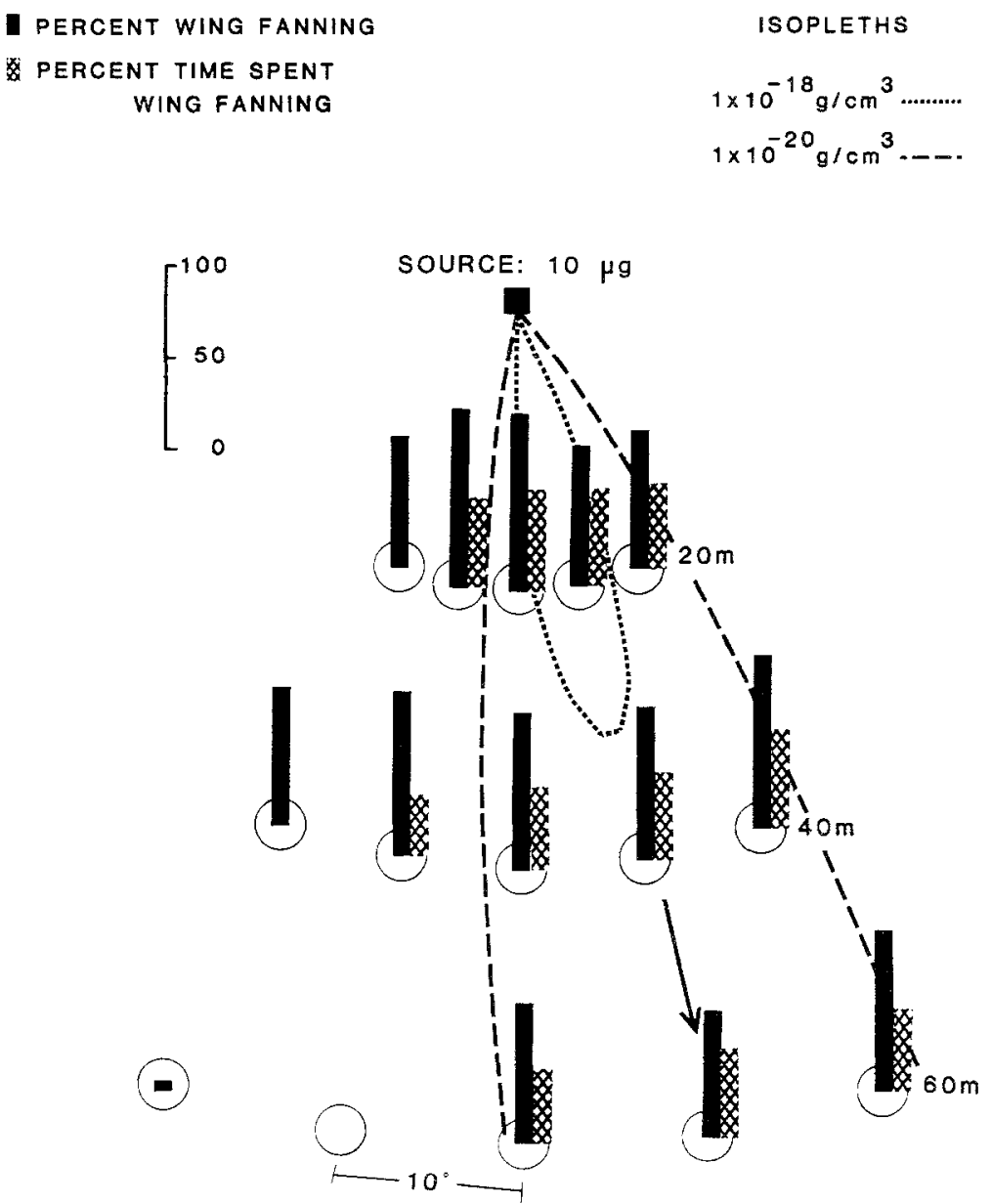

(d)

FIG. 4. (Continued) 


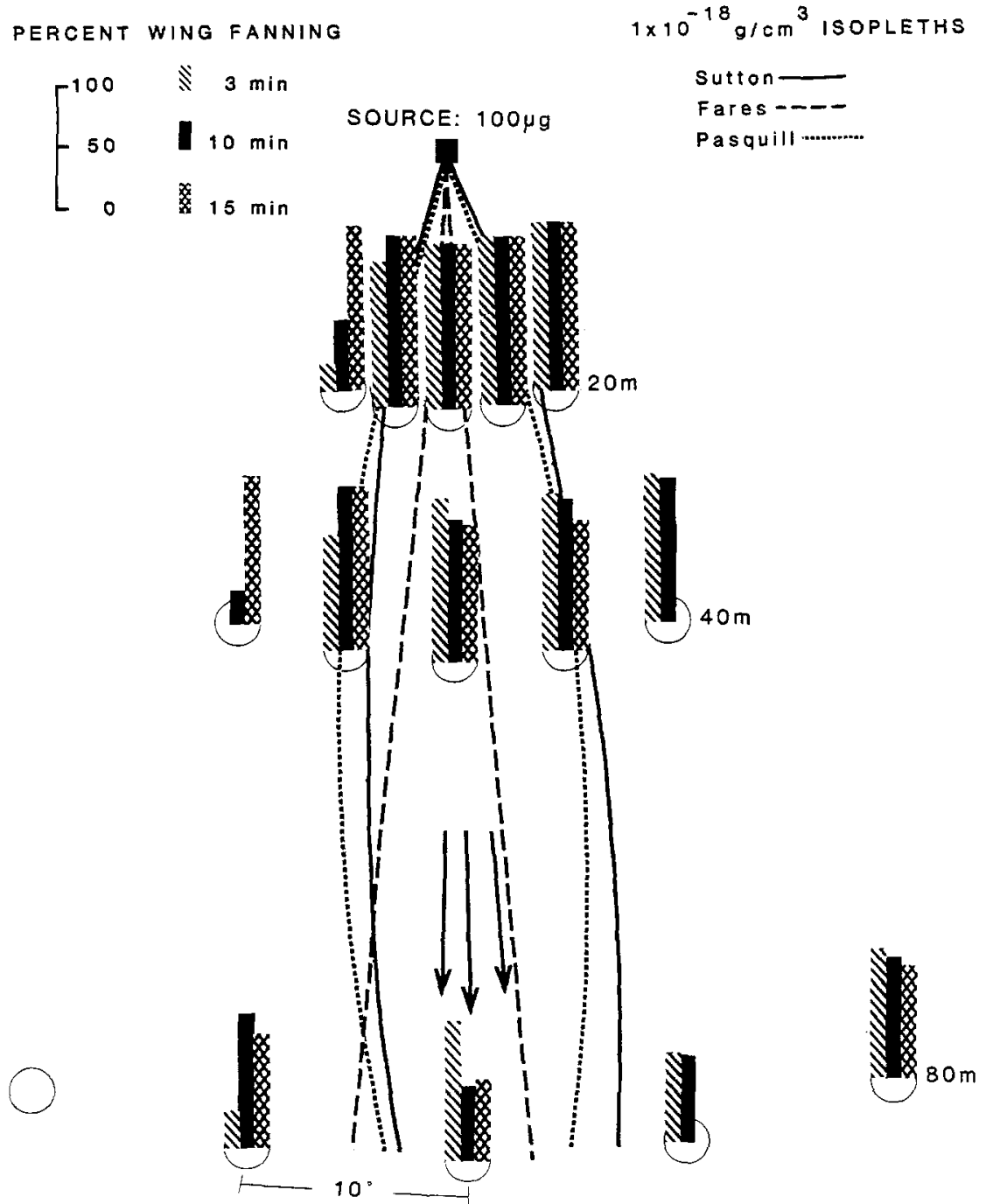

(a)

FIG. 5. $(\mathrm{a}-\mathrm{d})$ The $1 \times 10^{-18}$ concentration isopleths predicted by the Sutton model and the Gaussian plume model with Pasquill and Fares dispersion coefficients for a 3-, 10-, and 15-min sample interval, respectively, versus the percentage of males that wing fanned (corrected for background) during the three intervals at 15 locations downwind of a pheromone source. The plume centerlines for the three models differ due to changes in the mean wind direction as the sample interval increased. The percentage wing fanning at some locations actually decreased between 3 and 10 or $15 \mathrm{~min}$ because of the effects of the correction for background wing-fanning activity. 


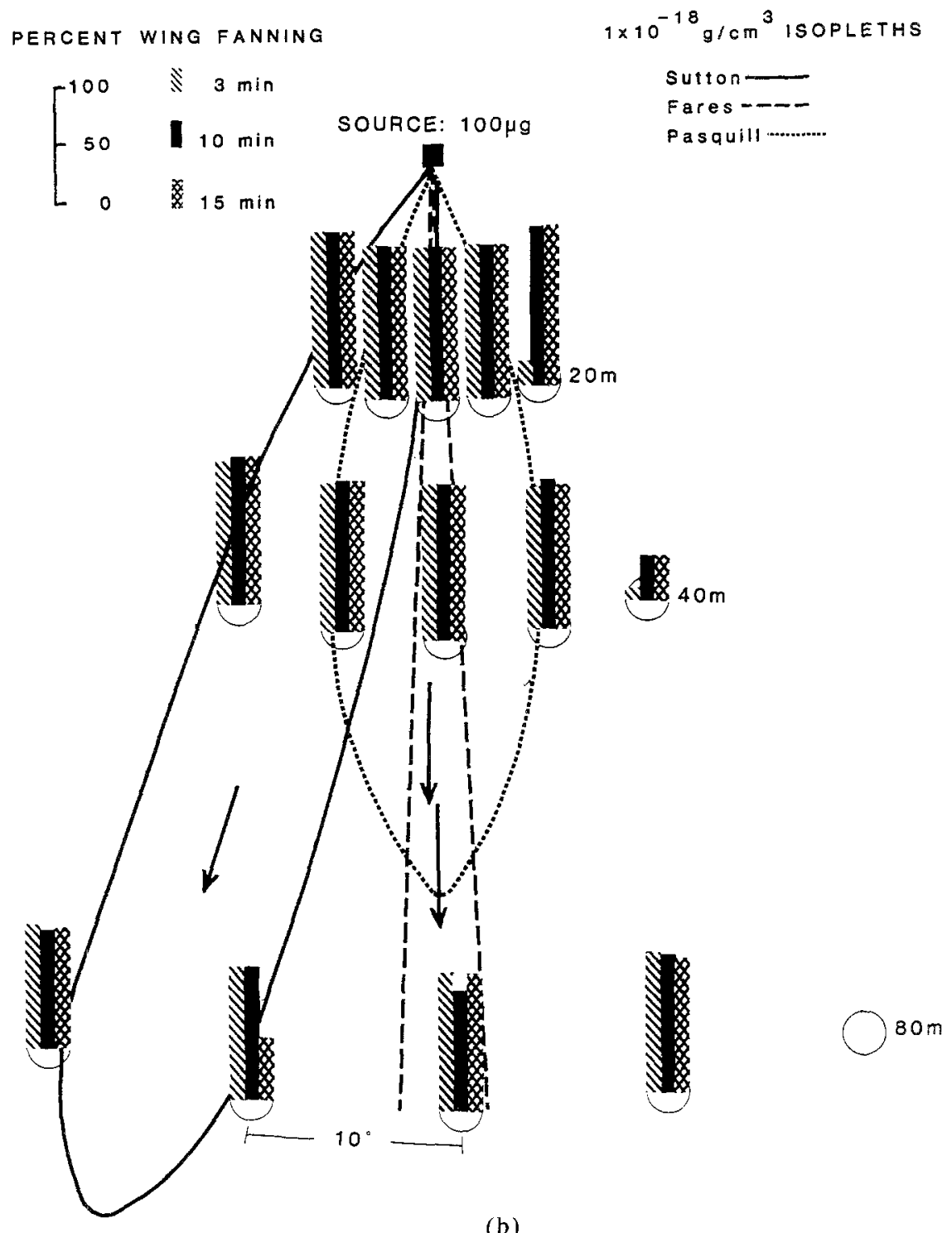

(b)

FIG. 5. (Continued) 


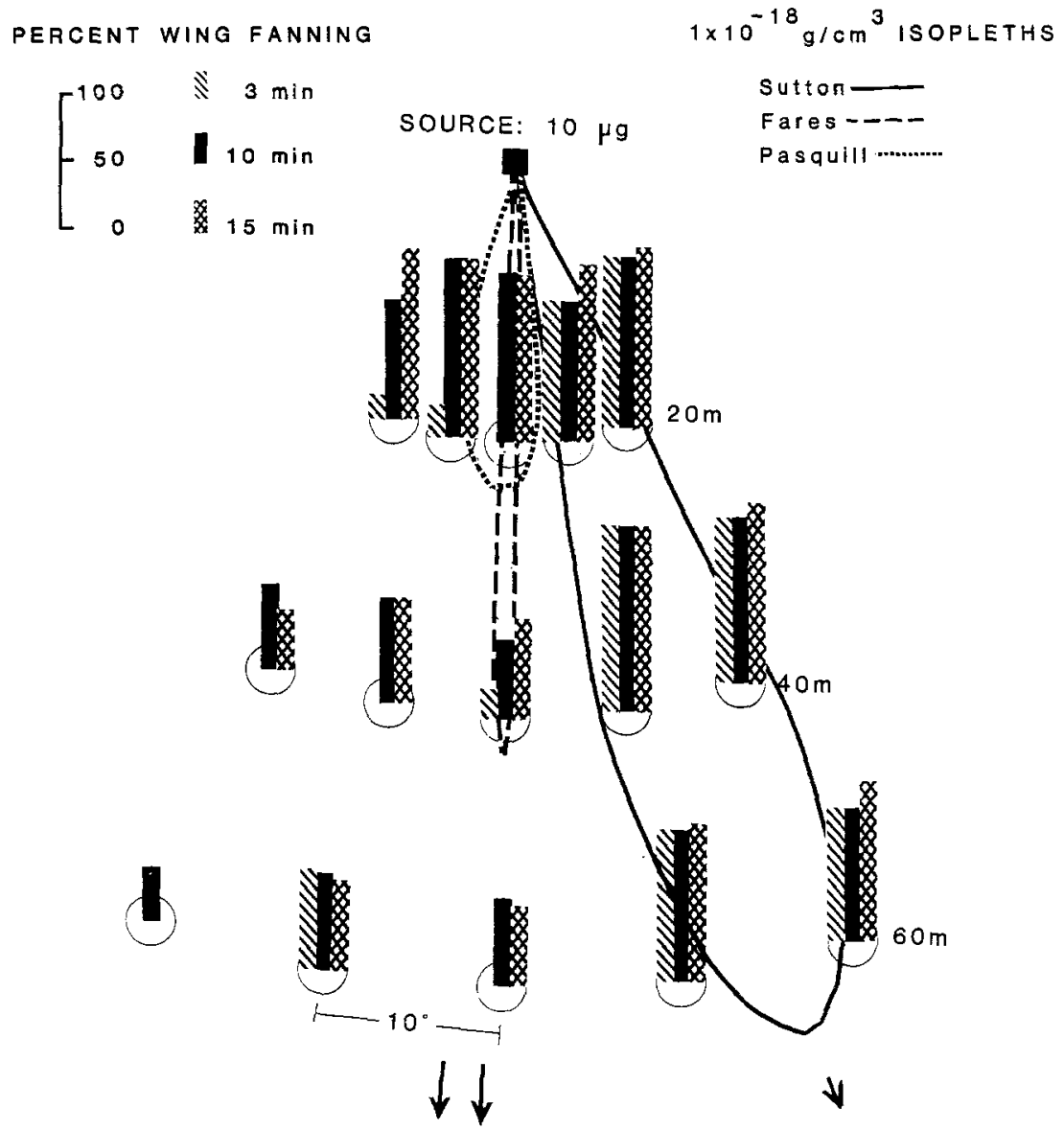

(c)

FIG. 5. (Continued) 


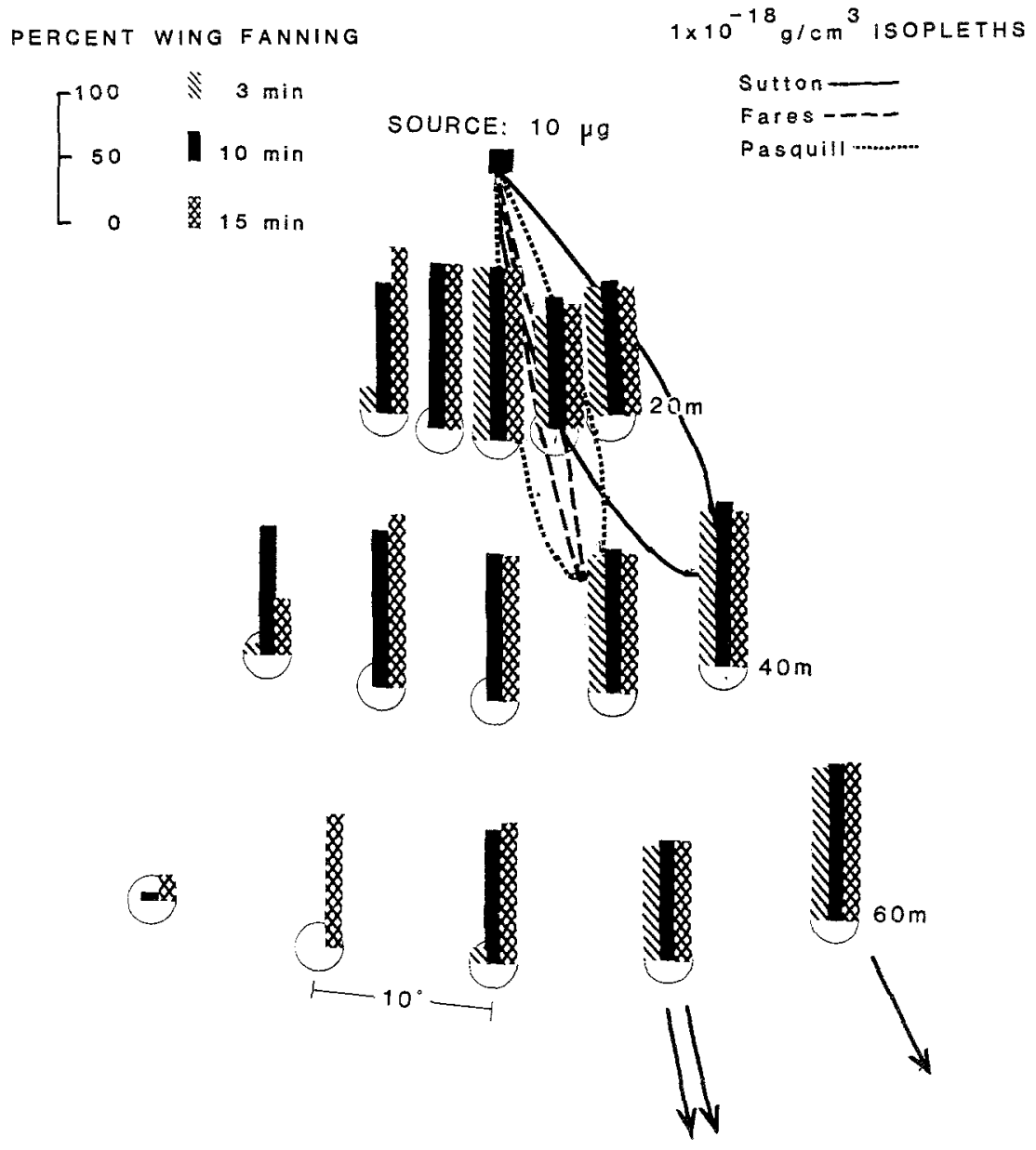

(d)

Fig. 5. (Continued) 
6). In other words, all these models underestimate the width of the active space at each distance.

This conclusion is corroborated by the probit analyses (Figure 7, Table 2), which indicate that there are no significant correlations among observed responses and the concentrations predicted by any of the three models. [If the models were accurate descriptions of concentrations of pheromone, the observed regression line should be similar to that obtained from the wind tunnel (Figure 6).] At all distances from the source ( 20 and $80 \mathrm{~m}$ ) and at both release rates (100-and $10-\mu \mathrm{g}$ dispensers), the slope of the regression line was not significantly different from zero. Conversion of pheromone concentration to pheromone flux had a negligible effect on the calculated regression lines for any model because the conversion entailed multiplying the concentration by the wind speed (values close to $1 \mathrm{~m} / \mathrm{sec}$ ). The difference caused by this conversion was miniscule when plotted on an abscissa covering many orders of magnitude.

At 20 and $80 \mathrm{~m}$ the width of the plume predicted by the Gaussian plume model using the dispersion coefficients of Fares et al. (1980) is much smaller than the width of the Sutton and Pasquill models, despite the facts that the sample intervals compared to the Sutton model were longer ( 15 vs $3 \mathrm{~min}$ ) and

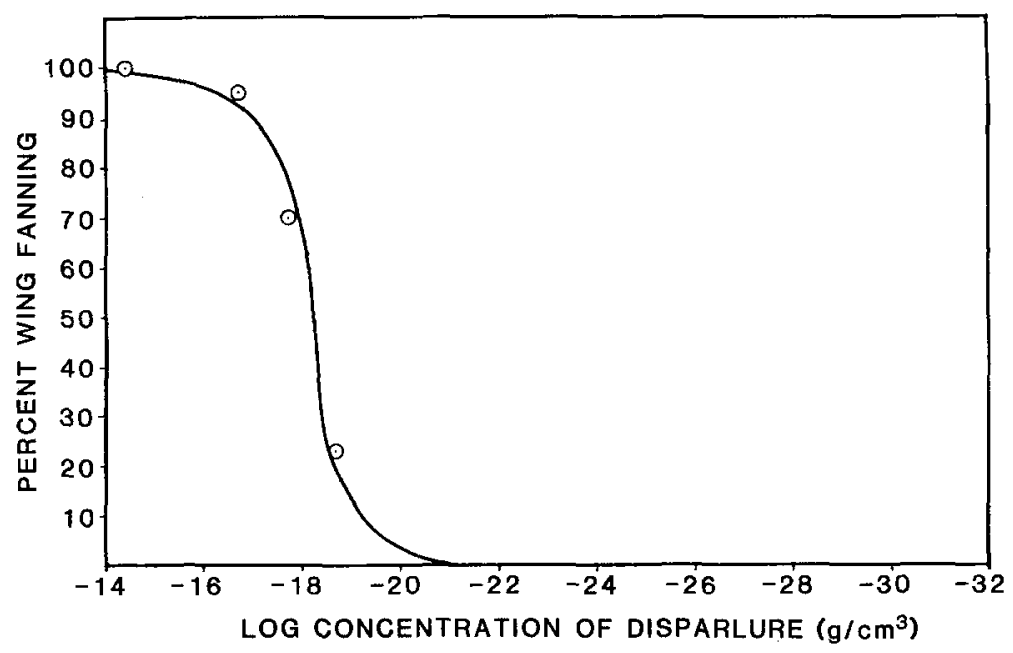

FIG. 6. Percentage wing-fanning responses versus estimated (+)-disparlure concentration in a wind tunnel at $24^{\circ} \mathrm{C}$ (Hagaman and Cardé, 1983). Concentrations estimates assume that $(+)$-disparlure is evenly distributed within a $15-\mathrm{cm}$-wide plume at the site of the males. Release rates for dispenser doses of 1000 and $100 \mathrm{ng}$ were measured by residue analysis (Cardé and Hagaman, 1983) and extrapolated in decade steps to 10 and $1 \mathrm{ng}$ from the measured rate at $100 \mathrm{ng}$. The probit regression line was calculated by the method of Finney (1971). 

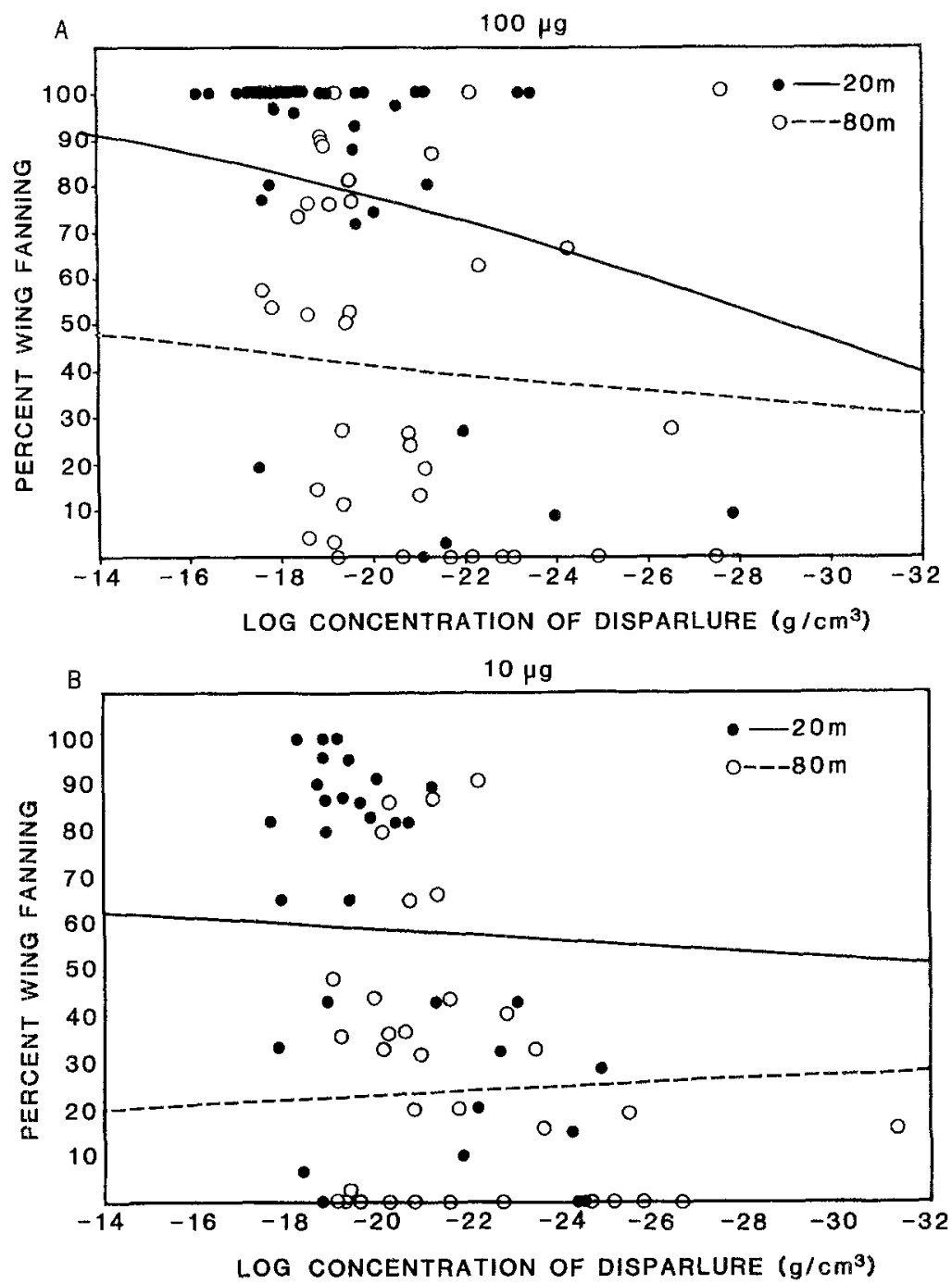

FIG. 7.(a, b) Regression lines generated by probit analysis at each rack location of the pheromone concentration predicted by the Sutton and Gaussian plume models for a $10-$ and $100-\mu \mathrm{g}$ source, respectively, at 20 and $80 \mathrm{~m}$ versus the observed percentage wing-fanning response (corrected for background) for each rack.

the dispersion coefficients were derived from studies conducted beneath a forest canopy, where mechanical turbulence is enhanced. Furthermore, the model of Fares et al. predicted higher pheromone concentrations at $80 \mathrm{~m}$ than at $20 \mathrm{~m}$ along all directions displaced by more than ca. $2^{\circ}$ from the mean plume centerline in contrast to the predictions of the other two models. 


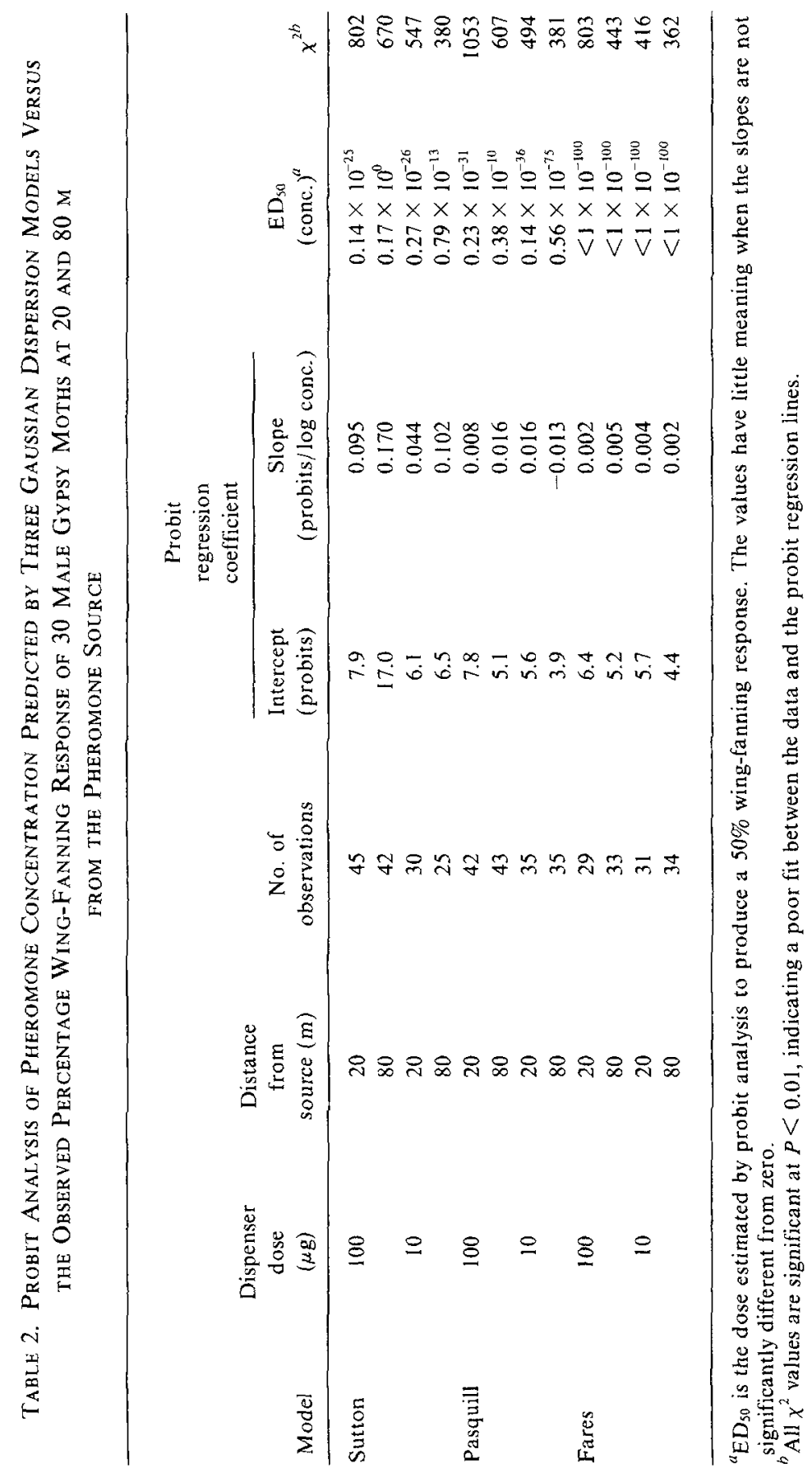




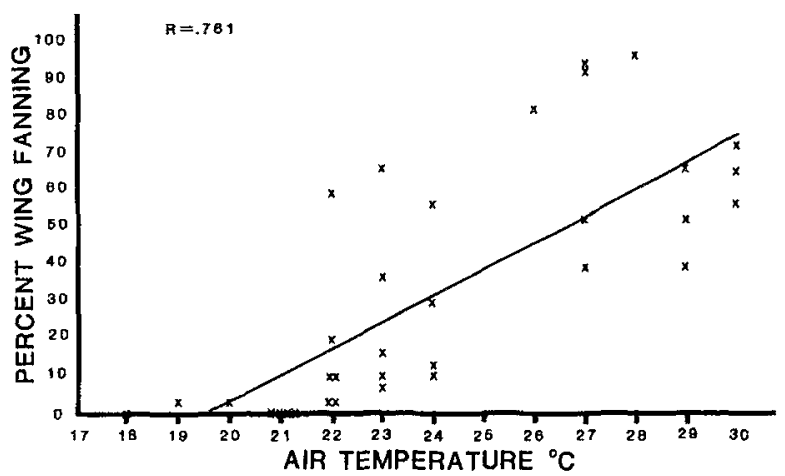

FIG, 8. Correlation of air temperature and percentage of males exhibiting spontaneous wing-fanning activity (i.e., $15 \mathrm{sec}$ or longer) during the first $10 \mathrm{~min}$ of the period prior to pheromone release.

The spontaneous wing-fanning activity during the prepheromone period increased with increasing temperature (Figure 8). It is also likely that increasing temperature lowered the threshold of the wing-fanning response to pheromone as shown in wind tunnel experiments (Cardé and Hagaman, 1983). Temperature also has a slight effect upon the rate of pheromone release from the dispenser, but this effect is small compared to the effect of changes in concentration on the moth's responsiveness.

\section{DISCUSSION}

Characteristics of Time-Average Gaussian Models. The three models are "Gaussian" in that they assume that the average concentration of airborne material released from a point source follows a normal (Gaussian) distribution along any axis perpendicular to the mean downwind direction. These models were derived from experiments in which tracer substances were released from a source and recovered in samplers arrayed downwind for the duration of a specific sample interval. The width of the plume, which is governed by the rate of turbulent dispersion, is expressed in terms of the vertical and horizontal dispersion coefficients. In general, longer sample intervals give rise to wider plumes (Slade, 1968, p. 57; Mason, 1973). The material is distributed at a lower concentration over a larger area. Few pheromone biologists have appreciated that these models apply only to the same specific sample interval as the experiments from which the dispersion coefficients were derived. For this reason we have correlated the model predictions to the wing-fanning responses that occurred during the appropriate interval ( $3 \mathrm{~min}$ for Sutton's model, $10 \mathrm{~min}$ for Pasquill's dispersion 
coefficients, $15 \mathrm{~min}$ for coefficients used by Fares et al.). The rate of dispersion and the values of the dispersion coefficients also depend upon the terrain and atmospheric conditions.

Comparison of Sutton and Gaussian Plume Models. In Sutton's model $(1947,1953)$ the vertical and horizontal dispersion coefficients $C_{z}$ and $C_{y}$ are constant under a given set of terrain and atmospheric conditions. Most applications of Sutton's model to pheromone dispersion have utilized the "typical" values," $C_{z}=0.2 \mathrm{~cm}^{1 / 8}, C_{y}=0.4 \mathrm{~cm}^{1 / 8}$, and $n=0.25$, which Sutton (1953, p. 292) suggested were appropriate for neutral atmospheric conditions over level ground under light winds. In theory, Sutton's dispersion coefficients could be calculated for any number of terrain and atmospheric conditions. However, atmospheric science has largely abandoned the Sutton model in favor of the more general Gaussian plume model in which the dispersion coefficients are measured experimentally for a given set of conditions instead of the theoretical derivations from other variables including the vertical wind speed profile attempted by Sutton (Mason, 1973). In contrast to Sutton's model, the dispersion coefficients in the Gaussian plume model are functions of the downwind distance $(x)$, which does not appear explicitly in Eq. (4). These coefficients are equivalent to the standard deviation of the vertical and horizontal distribution of concentration along any axis perpendicular to the mean wind direction. Thus, a great advantage of the Gaussian plume model is that it can be easily applied to a variety of atmospheric stabilities.

Neutral atmospheric conditions as required by the typical values of Sutton's dispersion coefficients only sometimes prevail. Unstable conditions occur most often during the day, when the ground absorbs heat from the sun and transmits it to the air immediately above, giving rise to convective updrafts and vertical mixing. Stable or inversion conditions occur most often at night, when radiant heat loss from the ground leads to cool air at ground level with warmer air above. However, daytime inversions may prevail beneath a closed forest canopy because the air at canopy level is heated by the sunlit foliage, with cooler air below. Therefore, the argument of Fares et al. (1980), that higher turbulence associated with midday temperature causes rapid dispersion of the plume, may not apply in forests with a closed canopy.

The differences among various forms of the Gaussian plume model mainly involve different values or functions chosen for the dispersion coefficients. The coefficients used in the model of Fares et al. (1980) were derived from a study conducted beneath a forest canopy. Given the long sampling time ( $15 \mathrm{~min}$ ) compared with the Sutton model and the mechanical turbulence introduced by the trees, it is surprising that the dispersion coefficients in Fares' model increase so slowly with downwind distance compared with the other Gaussian models.

Effect of Wind Speed: Flux vs Concentration. All the Gaussian dispersion models are inverse functions of wind speed. The size of the active 
spaces shrinks as the wind speed increases. Several previous studies have documented this effect with pheromone communication (Nakamura, 1976; Shapas and Burkholder, 1978). This phenomenon is caused principally by the dilution effect of eluting a given amount of pheromone into a larger "initial" volume. Wind speed also affects the rate of expansion of the pheromone plume. Wind speed affects the power spectrum of turbulent eddies that determine the rate of dispersion. For this reason the dispersion coefficients $\left(C_{y}, C_{z}\right)$ in the Sutton equation are themselves functions of the mean wind speed. The latter effect is ignored when typical values are used for $C_{y}$ and $C_{z}$, and in any case, it is small relative to the dilution effect. We did not attempt to document the effect of wind speed on the maximum distance of communication because we made observations at only three distances simultaneously and therefore we did not have a good measure of the length of the active space.

The moth response, moreover, is mediated by the number of molecules per second adsorbed by the antennae, a phenomenon more closely related to the flux $\left(\mathrm{g} / \mathrm{cm}^{2} \mathrm{sec}\right)$ of the pheromone through the antennae than the concentration $\left(\mathrm{g} / \mathrm{cm}^{3}\right)$. Since flux increases in direct proportion to the wind speed, the dilution effect is canceled. In our experiments conversion from concentration to flux did little to improve the performance of the models in predicting percentage wing fanning.

Instantaneous vs Time-Average Models. The Sutton model and the Gaussian plume model considered here estimate the average concentration (or flux) of pheromone for sample intervals of several minutes. Wright (1958) and Aylor et al. (1976) have noted that the actual plume experienced by a moth at any instant in time is by comparison very narrow and high in concentration. The plume meanders with the large-scale turbulent eddies such that a sampler fixed in space downwind of a source will experience no pheromone most of the time, interspersed by short intervals of high concentration. Moths presumably respond not to average concentrations of pheromone but to the "instantaneous" concentrations above a certain threshold. A brief exposure to a sufficiently high concentration will produce a wing-fanning response, even though the average concentration (over several minutes) at a particular site is below threshold. Therefore the "active space" of a pheromone (defined as the volume in space within which the concentrations are above the moth response threshold) will be larger for a given sample interval than that predicted by the Sutton or the Gaussian plume models. This explains why we observed wing-fanning responses at locations where the average concentration predicted by any of the three Gaussian models was several orders of magnitude below that which produced a similar response in the wind tunnel. This occurred even though we applied the Gaussian model to wing-fanning behavior that occurred over the appropriate time intervals for which they were designed.

Unfortunately there exists to date no comprehensive treatment of 
dispersion that can supplant the Gaussian models. The instantaneous plume models derived from the work of Batchelor (1952) and developed for pheromone dispersion by Aylor et al. (1976) and Miksad and Kittredge (1979) predict concentrations at locations fixed in reference to the meandering plume centerline. To apply such models to locations fixed in space we would need a description of plume meander as well.

Correlation of Wind Direction with Moth Response. The association between the wind direction measured at the source and the subsequent onset of wing-fanning activity at locations downwind along that direction (Figure 3 , Table 1) provides circumstantial support for the simple dispersion model of David et al. (1982). The model conceives of the pheromone plume as a continuous series of pheromone "parcels," each of which travels in a straight line after leaving the source, although the trajectory of consecutive parcels varies continually, as measured by the changing direction of a windvane. However, the fact that the association is not very strong suggests that, at least for the woodlot situation, at distances of $20 \mathrm{~m}$ or more the model is at best an approximation. Presumably the trajectory of individual parcels is influenced by collision with trees. However, a substantial proportion of the lack of correlation between the measured wind direction and the subsequent occurrence of wing fanning is undoubtedly due to the facts that wind direction samples occurred only at $12-\mathrm{sec}$ intervals and that the wind direction sensor was positioned $10 \mathrm{~m}$ from the source.

Characteristics of the Behavioral Assay. Neither of the two methods for estimating percentage wing-fanning response was a completely satisfactory measure of average pheromone concentration during the sample interval. The first method, which focused on the proportion of moths that responded at any time during the interval (corrected for background), is clearly a measure of peak, not average, concentration. The second method, based upon the mean number of seconds spent wing fanning, is related to average concentration, but it incorporates a bias caused by the continuation of wing-fanning behavior following removal of the pheromone stimulus (Figure 2). Rack locations where the response occured late in the 15 -min interval would show less time spent wing fanning than racks where the response occured early, even though both experienced the same average concentration. This would occur because the wing-fanning response would continue at the early location throughout much of the interval.

The threshold of wing-fanning response was also undoubtedly influenced by the air temperature as demonstrated in the wind tunnel (Carde and Hagaman, 1983). Baker and Roelofs (1981) have shown that the size of the active space of the oriental fruit moth, Grapholitha molesta, pheromone varies with air temperature. Some of the variability associated with the probit regression lines (Figure 7, Table 2) was undoubtedly due to daily variation in temperature. 


\section{SUMMARY AND CONCLUSION}

Time-average Gaussian dispersion models have been used to describe the size and shape of the pheromone active space or to estimate behavioral thresholds ever since they were first applied to pheromones by Wright (1958) and Bossert and Wilson (1963). This has occurred despite the arguments of Wright (1958) and Aylor et al. (1976) that instantaneous rather than average concentrations of pheromone determine responses and thus determine the size and shape of the active space. Furthermore, these models have generally been used by pheromone biologists without regard to the sample intervals or the terrain and atmospheric conditions to which they apply. Our results underscore the inadequacies of Gaussian dispersion models for describing pheromone active spaces. Even though we applied these models to the appropriate sample intervals and even though we attempted to use dispersion coefficients appropriate to the measured wind turbulence (standard deviation of the wind azimuth) and (for Fares' coefficients) appropriate to forest conditions, the pheromone concentrations predicted by these models at locations where we observed male gypsy moth wing fanning were several orders of magnitude lower than the minimum concentrations known to elicit wing fanning in a wind tunnel. This undoubtedly occurred because the moths were responding to the peak instantaneous concentrations rather than the average concentrations predicted by these time-average Gaussian models.

Acknowledgments - We would like to thank all those who assisted us in the field including John Vagnetti, Lonnie Young, Nancy Cotrill, Lonnie Janzen, Wayne Forrester, and Pam Polhemus. We would also like to thank Wayne Forrester, Liga Dindonis, and Joe Kelly for help with data analyses and Ralph Charlton for reviewing the manuscript. We thank Y. Fares for lending us a copy of the TRC-343 dispersion data. We are very grateful to Dr. Charles Schwalbe of the USDA-APHIS, PPQ Methods Development Laboratory, for generously supplying male gypsy moths. This research was supported by grants from the National Science Foundation (PCM-7912014) and the USDA Gypsy Moth Program

\section{REFERENCES}

AyLor, D.E., Parlange, J.-Y., and Granetr, J. 1976. Turbulent dispersion of disparlure in the forest and male gypsy moth response. Environ. Entomol. 5:1026-1032.

BAKER, T.C., and ROELOFS, W.L. 1981. Initiation and termination of Oriental fruit moth male response to pheromone concentrations in the field. Environ. Entomol. 10:211-218.

BATCHELOR, G.K. 1952. Diffusion in a field of homogeneous turbulence. II. The relative motion of particles. Proc. Cambr. Phil. Soc. 48:345-362.

Bell, R.A., Owens, C.D., Shapiro, M., and TARdif, J.R. 1981. Mass rearing and virus production, pp. 599-665, in The Gypsy Moth: Research Towards Integrated Pest Management. USDA Tech. Bull. No. 1584.

BOSSERT, W.H., and WILSON, E.O. 1963. The analysis of olfactory communication among animals. J. Theoret. Biol. 5:443-469.

Cardé, R.T., Doane, C.C., and Roelofs, W.L. 1974. Diel periodicity of male sex pheromone responses and female attractiveness in the gypsy moth (Lepidoptera: Lymantriidae). Can. Entomol. 106:479-484. 
Cardé, R.T., Doane, C.C., and Farnum, D.G. 1978. Attractancy to male gypsy moths of $(+)$-disparlures synthesized by different procedures. Environ. Entomol. 7:815-816.

CARDÉ, R.T., and HAGAMAN, T.E. 1979. Behavioral responses of the gypsy moth in a wind tunnel to air-borne enantiometers of disparlure. Environ. Entomol. 8:475-484.

CARDÉ, R.T., and HaGAmAN, T.E. 1983. Influence of ambient and thoracic temperatures upon sexual behaviour of the gypsy moth, Lymantria dispar Physiol. Entomol. 8:7-14.

David, C.T., Kennedy, J.S., Ludlow, A.R., Perry, J.N., and Wall, C. 1982. A re-appraisal of insect flight towards a distant, point source of wind-borne odor. J. Chem. Ecol. 9:1207-1215.

Elkinton, J.S., and CARDÉ, R.T. 1984. Odor dispersion. In Chemical Ecology of Insects. Chapman and Hall, London.

Fares, Y., Sharpe, P.J.H., and Magnuson, C.E. 1980. Pheromone dispersion in forests. $J$. Theoret. Biol. 84:335-359.

Finney, D.J. 1971. Probit Analysis, 3rd ed. Cambridge University Press, London.

GiFFORD, F.A., JR. 1968. An outline of theories of diffusion in the lower layers of the atmosphere, pp. 65-116, in D.H. Slade (ed.) Meteorology and Atomic Energy. U.S. Atomic Energy Commission, Oak Ridge, Tenn.

HAGAMAN, T.E., and CARDÉ, R.T. 1984. Effect of pheromone concentration on the organization of pre-flight behaviors of the male gypsy moth, Lymantria dispar (L.). J. Chem. Ecol. (10:17-23).

Mason, C.J. 1973. Meteorological dispersion models and their applications to aerobiological problems. Presented at Workshop/Conference III, "Ecological Systems Approaches to Aerobiology," US/IBP Aerobiology Program, University of Michigan, Ann Arbor.

Miksad, R.W., and Kittredge, J. 1979. Pheromone aerial dispersion: A filament model. 14th Conf. Agr. Forest Meteorol. Am. Meteorol. Soc., pp. 238-243.

Murlis, J., and Jones, C.D. 1981. Fine-scale structure of odour plumes in relation to insect orientation to distant pheromone and other attractant sources. Physiol. Entomol. 6:71-86.

Nakamura, K. 1976. The effect of wind velocity on the diffusion of Spodoptera litura (F.) sex pheromone. Appl. Entomol. Zool. 11:312-319.

Pasquill, F. 196I. The estimation of the dispersion of wind-borne material. Met. Mag. 90:33-49.

PAsquill, F. 1974. Atmospheric Diffusion. Halsted Press-John Wiley, New York.

RoELOFs, W.L. 1978. The threshold hypothesis for pheromone perception. J. Chem. Ecol. $4: 685-699$.

Shapas, T.J., and Burkholder, W.E. 1978. Patterns of sex pheromone release from adult females, and effects of air velocity and pheromone release rates on theoretical communication distances in Trogoderma glabrum. J. Chem. Ecol. 4:395-408.

Slade, D.H. (ed.). 1968 Meteorology and Atomic Energy. U.S. Atomic Energy Commission, Oak Ridge, Tenn.

SutTon, O.G. 1947. The problem of diffusion in the lower atmosphere. Q.J. Roy. Meteorol. Soc. $73: 257-281$.

Surton, O.G. 1953. Micrometeorology. McGraw-Hill, New York, 333 pp.

WRIGHT, R.H. 1958. The olfactory guidance of flying insects. Can. Entomol. 90:81-89. 